\title{
Neonatal injury alters adult pain sensitivity by increasing opioid tone in the periaqueductal gray
}

\author{
Jamie L. LaPrairie and Anne Z. Murphy* \\ Neuroscience Institute, Georgia State University, Atlanta, GA, USA
}

\section{Edited by:}

Larry J. Young, Emory University

School of Medicine, USA;

Yerkes National Primate Research

Center, USA

\section{Reviewed by:}

Wendy Sternberg, Haverford College, USA

Mathew Ennis, The University of Tennessee Health Science Center, USA

\section{${ }^{*}$ Correspondence:}

Anne Z. Murphy, Neuroscience Institute, Georgia State University, PO Box 5030, 38 Peachtree Center Ave, 806 GCB, Atlanta, GA 30303, USA.

e-mail: amurphy@gsu.edu
Studies in both rodents and humans have shown that acute inflammatory pain experienced during the perinatal period produces long-term decreases in pain sensitivity (hypoalgesia) (Grunau et al., 1994a, 2001; Ren et al., 2004; LaPrairie and Murphy, 2007). To date, the mechanisms underlying these long-term adaptations, however, have yet to be elucidated. The present studies tested the hypothesis that neonatal inflammatory pain induces an upregulation in endogenous opioid tone that is maintained into adulthood, and that this increase in opioid tone provides the underlying mechanism for the observed hypoalgesia. On the day of birth (P0), inflammatory pain was induced in male and female Sprague-Dawley rats by intraplantar administration of carrageenan (CGN; 1\%). In adulthood (P60), these animals displayed significantly increased paw withdrawal latencies in response to a noxious thermal stimulus in comparison to controls. Systemic administration of the brain-penetrant opioid receptor antagonist naloxone $\mathrm{HCl}$, but not the peripherally restricted naloxone methiodide, significantly attenuated the injury-induced hypoalgesia. Direct administration of naloxone $\mathrm{HCl}$ or antagonists directed at the mu or delta opioid receptors into the midbrain periaqueductal gray (PAG) also significantly reversed the injury-induced hypoalgesia in adult rats. Parallel anatomical studies revealed that inflammatory pain experienced on the day of birth significantly increased betaendorphin and met/leu-enkephalin protein levels and decreased opioid receptor expression in the PAG of the adult rat. Thus, early noxious insult produces long-lasting alterations in endogenous opioid tone, thereby profoundly impacting nociceptive responsiveness in adulthood.

Keywords: neonate, inflammation, pain, mu receptor, delta receptor, naloxone

\section{INTRODUCTION}

The impact of neonatal pain on developing nociceptive circuitry, nociceptive processing and the subsequent perception of pain has been the focus of a significant amount of research within the last decade. Evidence from clinical and animal research suggests that exposure to noxious stimuli early in life may result in lasting changes in sensory processing (Grunau et al., 1994a; Ren et al., 2004; LaPrairie and Murphy, 2007). For example, in preterm infants, a higher frequency of invasive procedures is associated with significantly dampened pain responses at 32 weeks of age (Grunau et al., 2001). Moreover, premature infants with NICU experience display decreased behavioral responses to heel-lance and inoculation at 8 months (Johnston et al., 1996; Oberlander et al., 2000), and are rated by parents as less sensitive to pain compared to children with no NICU experience at 18 months of age (Grunau et al., 1994b). Indeed, alterations in nociception are not transient in nature, such that both full- and preterm infants with prior NICU experience display decreased pain sensitivity at 14 years of age (Hermann et al., 2006).

Consistent with the human literature, experimental animal studies have also shown that neonatal noxious insult induces widespread changes in nociceptive processing. For example, in rats, neonatal intraplantar inflammation induces long-lasting and significant hypoalgesia in both the previously injured and uninjured paws, and changes in pain sensitivity have been reported for the tail and viscera as well (Al-Chaer et al., 2000; Ren et al., 2004; Wang et al., 2004; DeBerry et al., 2007; LaPrairie and Murphy, 2007). A generalized decrease in nociceptive sensitivity as a consequence of repetitive foot shock, surgical incisions, and intraplantar formalin injections has also been reported (Shimada et al., 1990; Bhutta et al., 2001; Sternberg et al., 2005). In addition, neonatally injured rats display a hypersensitive response following re-injury in adulthood and a significantly reduced rate of recovery, with similar findings reported in humans (Ren et al., 2004; LaPrairie and Murphy, 2007). Interestingly, all of these long-term consequences associated with neonatal inflammatory insult are exacerbated in females (LaPrairie and Murphy, 2007). To date, however, the mechanisms underlying neonatal injury-induced changes in sensory processing have yet to be elucidated.

The objective of the present study was to determine if the longterm decreases in nociceptive responsiveness induced by neonatal inflammatory insult are due to alterations in endogenous pain modulation. Behavioral and anatomical studies were conducted to test our hypothesis that neonatal injury-induced hypoalgesia is mediated by an increase in central opioid tone resulting from increased activation of descending nociceptive inhibitory pathways.

\section{MATERIALS AND METHODS SUBJECTS}

Time-pregnant Sprague-Dawley rats (Zivic Miller) were obtained on the 14th day of gestation (E14) and housed individually. Animals 
were maintained on a 12:12 h light:dark cycle, with food and water available ad libitum. All litters were reared identically, weaned at P21, and housed with same-sex littermates in groups of 2-3. All experiments were approved by the Georgia State University Animal Care and Use Committee and were conducted in strict compliance with the guidelines for pain research established by the International Association for the Study of Pain (IASP).

\section{EARLY LIFE MANIPULATIONS}

Acute neonatal inflammation was induced by unilateral injection of carrageenan (CGN; 1\% soln in saline; $5 \mu \mathrm{l}$; Sigma, St. Louis MO) into the plantar surface of the right hindpaw within $12 \mathrm{~h}$ of birth on $\mathrm{P} 0$. This inflammatory agent provides a well-established model of acute local inflammatory pain that persists for $12-72 \mathrm{~h}$ (Ren et al., 2004). Control animals received intraplantar sterile saline or were "handled" in a similar manner and returned to their home cage.

\section{NOCICEPTIVE BEHAVIORAL TESTING}

Thermal testing was conducted using the Paw Thermal Stimulator (UCSD, San Diego, CA, USA). Briefly, animals were placed in a clear plastic testing chamber on a glass surface and allowed to acclimate for a minimum of 30 min prior to testing. A radiant beam of light beneath the glass base was directed at the plantar surface of the each hindpaw and the withdrawal reflex latency was electronically measured (in seconds) (Hargreaves et al., 1988). Intact male and cycling female rats were tested separately. The average withdrawal latency of three trials was taken; all trials were separated by a 5-min inter-trial interval. Application of the thermal stimulus to either the left (previously uninjured) or right (previously injured) paw was randomly determined. While hypoalgesia is present in both paws (LaPrairie and Murphy, 2007), only right paw latencies are reported here. To avoid potential tissue damage, a 20-s automatic termination of the heat stimulus (approximately $2 \times$ baseline latency) was imposed if a paw withdrawal did not occur. The testing apparatus was thoroughly cleaned between sessions. The same investigator whom was blinded to the neonatal treatment conducted all behavior tests.

\section{DRUG ADMINISTRATION}

To test the hypothesis that neonatal injury-induced hypoalgesia was due to increased endogenous opioid tone, naloxone $\mathrm{HCl}$ ( $1 \mathrm{mg} \mathrm{kg}$ s.c.; Sigma, St. Louis, MO, USA) dissolved in saline to desired concentration was administered $10 \mathrm{~min}$ prior to paw withdrawal latency (PWL) determination on P60. To test whether alterations in opioid tone were peripherally mediated, the peripherally restricted opioid antagonist, naloxone methiodide (1 mg/kg s.c.; Sigma, St. Louis, MO, USA), was administered systemically 15 min prior to testing in adulthood. The doses used were selected based on our previous studies (Ji et al., 2006; LaPrairie and Murphy, 2007).

For intracerebroventricular (i.c.v.) or intra-PAG injections, intact males $(n=48)$ and cycling females $(n=52)$ were deeply anesthetized with a cocktail of ketamine/xylazine/acepromazine $(50 \mathrm{mg} /$ $\mathrm{kg} / 3.3 \mathrm{mg} / \mathrm{kg} / 3.3 \mathrm{mg} / \mathrm{kg}$; i.p.; Henry Shein, Melville, NY, USA) and placed in a stereotaxic frame. A guide cannula (22G, C313G, PlasticOne Inc, Roanoke, VA, USA) was implanted at the following coordinates $(\mathrm{mm})$ for i.c.v. injections: Bregma: -1.0 ; mediolateral: 1.4; dorsoventral: 3.6. For PAG injections, a guide cannula was implanted at the following coordinates: lambda: +0.50; mediolateral:
0.65; dorsoventral: 5.8 as previously described (Loyd et al., 2008). PAG injections were unilateral, with the cannula located ipsilateral to the injured paw (right side). The ventrolateral PAG was targeted for injection as this region contains a high density of mu opioid receptors (Wang and Wessendorf, 2002).

On P60, naloxone $\mathrm{HCl}$ was injected i.c.v. $(1.0 \mu \mathrm{g} / 2.0 \mu \mathrm{l}$; Sigma, St. Louis, MO, USA) over a 2-min period. In subsequent experiments the following opioid antagonists were administered intra-PAG: naloxone $(0.5 \mu \mathrm{g} / 0.5 \mu \mathrm{l}), \mathrm{mu}$ antagonist CTOP $(0.5 \mu \mathrm{g} / 0.5 \mu \mathrm{l}$ and $7.5 \mu \mathrm{g} / 0.5 \mu \mathrm{l})$, delta antagonist naltrindole $(0.5 \mu \mathrm{g} / 0.5 \mu \mathrm{l}$ and $7.5 \mu \mathrm{g} / 0.5 \mu \mathrm{l})$ and kappa antagonist nor-BNI $(7.5 \mu \mathrm{g} / 0.5 \mu \mathrm{l})$. All antagonists were gifts from NIDA. Mu and delta antagonists and doses were administered in random order 15 min prior to testing. As nor-BNI is a permanent antagonist, all animals received this antagonist last (Craft et al., 2001). As a positive control, a separate group of animals were only administered nor-BNI. Nor-BNI was administered and testing followed $24 \mathrm{~h}$ later (Craft et al., 2001). Paw withdrawal latencies in response to noxious thermal stimulation were determined at 15, 30, 45, 60, 90 and 120 min post-injection. A minimum 72-h washout period between all drugs and doses was imposed. Injection sites were determined by administration of Pontamine Sky Blue (0.5 $\mu$ l, PAG; $2.0 \mu$ l, i.c.v.; Sigma Aldrich, USA) at the completion of the experiment. Brains were removed, sectioned, and sections mounted onto slides; all injections sites were verified histologically. Only animals with injection sites into the lateral ventricle or ventrolateral PAG (Bregma: -7.64 to -8.30 ) were used for further analysis.

\section{PERFUSION FIXATION}

At P60, a separate group of neonatally manipulated animals that were not used in the behavioral experiments were given a euthanizing dose of Nembutal (160 mg/kg; i.p.), and then perfused transcardially (descending aorta clamped) with $200 \mathrm{ml}$ of $0.9 \%$ sodium chloride containing $2 \%$ sodium nitrite as a vasodilator, followed by $250 \mathrm{ml}$ of $4 \%$ paraformaldehyde in $0.1 \mathrm{M}$ phosphate buffer containing 2.5\% acrolein (Polysciences, Warrington, PA, USA). Following fixation, a final rinse with the sodium chloride/sodium nitrite solution was used to remove residual acrolein from the animal. Immediately after perfusion, the brains were removed and the tissue stored at $4^{\circ} \mathrm{C}$ in $30 \%$ sucrose solution until sectioned. The brains were cut into $30-\mu \mathrm{m}$ coronal sections with a Leica $2000 \mathrm{R}$ freezing microtome (Leica Microsystems, Wetler, Germany) and stored freely floating in cryoprotectant-antifreeze solution (Watson et al., 1986) at $-20^{\circ} \mathrm{C}$ until immunohistochemical processing.

\section{IMMUNOCYTOCHEMISTRY}

A 1:6 series through the rostrocaudal axis of each brain was processed for immunohistochemical localization of mu opioid receptor, beta-endorphin, met-enkephalin or leu-enkephalin. Briefly, sections were removed from the cryoprotectant-antifreeze solution, rinsed extensively in potassium phosphate-buffered saline, and then reacted for $20 \mathrm{~min}$ in $1 \%$ sodium borohydride to remove excess aldehydes. Sections were then incubated in primary antibody solution in potassium phosphate buffer solution (KPBS) containing $0.1 \%$ Triton $\mathrm{X}$ for $1 \mathrm{~h}$ at room temperature, followed by $48 \mathrm{~h}$ at $4^{\circ} \mathrm{C}$. Mu immunoreactivity was identified using the polyclonal rabbit anti-MOR antibody at a concentration 
of 1:35,000 (Chemicon; Billerica, MA, USA). Beta-endorphin immunoreactivity was recognized using the polyclonal rabbit antibeta-endorphin antibody at a concentration of 1:30,000 (Peninsula Labs; Torrance, CA, USA). Met- and leu-enkephalin immunoreactivity were identified using the polyclonal rabbit anti-met-enkephalin and anti-leu-enkephalin antibodies at concentrations of 1:50,000 (Immunostar; Hudson, WI, USA) and 1:200,000 (Immunostar; Hudson, WI, USA), respectively. After rinsing in KPBS, the tissue was incubated for $1 \mathrm{~h}$ in biotinylated goat-anti-rabbit IgG (Jackson Immunoresearch, West Grove PA, USA; 1:200), rinsed again, and incubated for $1 \mathrm{~h}$ in avidin-biotin peroxidase complex (ABC Elite Kit, Vector, Burlingame, CA, USA; 1:10). After rinsing in KPBS and sodium acetate $(0.175 \mathrm{M} ; \mathrm{pH} 6.5)$, antigens were visualized using nickel sulfate-intensified 3,3' -diaminobenzidine solution containing $0.08 \%$ hydrogen peroxide in sodium acetate buffer. The reaction product was terminated after 20-30 min by rinsing in sodium acetate buffer. Sections were mounted out of saline onto gelatinsubbed slides, air dried overnight, dehydrated in a series of graded alcohols, cleared in xylene, and coverslipped with Permount.

\section{DENSITOMETRY}

The PAG was divided into three rostrocaudal levels: (Rostral: Bregma -6.72 to -7.04 ; Mid: Bregma -7.30 to -8.00 ; Caudal: Bregma -8.30 to -8.80$)$, and the lateral/ventrolateral PAG (PAGl/vl) was analyzed for each section as previously described (Loyd et al., 2008). The lateral/ventrolateral region was targeted based on previous studies demonstrating that this region contains a high density of MOR mRNA and protein (Commons et al., 2000; Wang and Wessendorf, 2002). Briefly, 12-bit grayscale images of each section were captured with a $2 \times, 4 \times$ and $20 \times$ objective on a Nikon Eclipse E800 microscope using a Sensys digital camera (Biovisions Technology; Exton, PA, USA). Quantitative analysis was performed using IP Spectrum software (Scanalytics; Fairfax, VA, USA). The PAGl/vl was sampled for three sections per animal and the average grayscale pixel value (ODU; optical density units) was recorded per rostrocaudal level. Measures were corrected for nonspecific binding by subtraction of background measures taken from areas lacking immunoreactivity adjacent to the PAGl/vl.

\section{RECEPTOR AUTORADIOGRAPHY}

Neonatally manipulated male and female rats were sacrificed on P60 by decapitation. Brains were quickly removed, flash-frozen on dry ice and stored at $-80^{\circ} \mathrm{C}$. Next, brains were sectioned at $20 \mu \mathrm{m}$ thickness with a Leica CM3050S cryostat, and immediately mounted onto Super-frost slides and stored at $-80^{\circ} \mathrm{C}$ until the time of assay. For radiographical processing, sections were allowed to thaw to room temperature and then immersed in $0.1 \%$ paraformaldehyde for $2 \mathrm{~min}$ to optimize tissue integrity. Sections then were rinsed in $50 \mathrm{mM}$ Tris- $\mathrm{NaCl}(\mathrm{pH} 7.4)$ at room temperature for $15 \mathrm{~min}$ followed by a 15 -min rinse in $50 \mathrm{nM}$ Tris ( $\mathrm{pH}$ 7.4). Next, the tissue sections were incubated for $60 \mathrm{~min}$ at room temperature in a solution of $50 \mathrm{mM}$ Tris ( $\mathrm{pH}$ 7.4) with $10 \mathrm{mM}$ $\mathrm{MgCl}_{2}$ and $0.1 \%$ bovine serum albumin. $3 \mathrm{~nm}[3 \mathrm{H}]-$ Naltrindole (20 Ci/mmol; NIDA) was added to label delta receptor binding or $1 \mathrm{~nm}[3 \mathrm{H}]-\mathrm{DAMGO}$ (56.8 Ci/mmol; Perkin Elmer/NEN, MA, USA) was added to label mu receptor binding. Following incubation, sections were washed three times at $10 \mathrm{~min}$ each in $50 \mathrm{mM}$ Tris- $\mathrm{HCl}$ ( $\mathrm{pH}$ 7.4) with $10 \mathrm{mM} \mathrm{MgCl}_{2}$ at room temperature, followed by a final dip in cold $\mathrm{dH}_{2} \mathrm{O}$. Sections were allowed to air-dry overnight and were then apposed to FujiFilm imaging plates along with $[3 \mathrm{H}]$-microscale standards (Perkin-Elmer/NEN, MA, USA) for 4 weeks. Film plates were processed using a FujiFilm BAS 5000. Autoradiographic [3H]receptor binding was quantified from film using MultiGauge software (FujiFilm, USA). [3H]-standards were used to convert uncalibrated optical density to disintegrations per minute (DPM). For analysis, the PAG was divided into three rostrocaudal levels as described above, and DPM were determined for the lateral/ventrolateral subdivision of each level. A mean for each level (rostral, mid, caudal) for each animal was then calculated.

\section{STATISTICAL ANALYSIS AND DATA PRESENTATION}

All values are reported as Mean \pm SEM. Behavioral data are expressed as raw withdrawal latencies. Significant main effects of neonatal treatment and sex were assessed using ANOVA or Repeated Measures ANOVA; $p<0.05$ was considered statistically significant. Sheffe post-hoc tests were conducted to determine significant mean differences between groups that were apriori specified. Anatomical data are expressed either as optical density units (ODU; immunohistochemistry) or disinigrations per minute (DPM; autoradiography). For data presentation, a representative animal from each experimental group was selected. Photomicrographs were generated using a Synsys digital camera attached to a Nikon Eclipse E800 microscope. Images were captured with IP Spectrum software and finalized in Adobe Photoshop 7.0. Alterations to the images were strictly limited to enhancement of brightness and contrast.

\section{RESULTS}

\section{NEONATAL INJURY ALTERS OPIOID TONE}

To test the hypothesis that neonatal injury results in upregulated opioid tone in adulthood, neonatally manipulated male and female rats received a systemic injection of the non-selective opioid antagonist naloxone $\mathrm{HCl}(1 \mathrm{mg} / \mathrm{kg}$; i.p.) or saline control $15 \mathrm{~min}$ prior to behavioral testing at P60. Neonatally injured ( $1 \%$ CGN) animals that were administered saline $(n=6-8 /$ sex $)$ in adulthood displayed significantly increased PWLs compared to control animals $(F(5,39)=53.54, p<0.05$; Figure 1A $)$. This injuryinduced hypoalgesia was significantly greater in neonatally-injured females compared to males, as previously reported (LaPrairie and Murphy, 2007). In contrast, neonatally injured males and females $(n=6-8 /$ sex $)$ that received systemic naloxone $\mathrm{HCl}$ in adulthood displayed PWLs of approximately 9-10 s, not significantly different from withdrawal latencies in uninjured control animals $(p>0.05$; Figure 1A). Indeed, opioid receptor blockade by systemic naloxone completely reversed the neonatal injury-induced hypoalgesia in both males and females, suggesting that the long-term hypoalgesia observed in neonatally injured animals is due to altered endogenous opioid tone.

\section{ALTERATIONS IN OPIOID TONE ARE CENTRALLY, AND NOT PERIPHERALLY, MEDIATED}

Opioid receptors are present both centrally and peripherally (Hiller et al., 1994). To determine whether changes in peripheral opioid tone contributed to effects observed with systemic naloxone $\mathrm{HCl}$, adult animals were administered the peripherally restricted opioid 


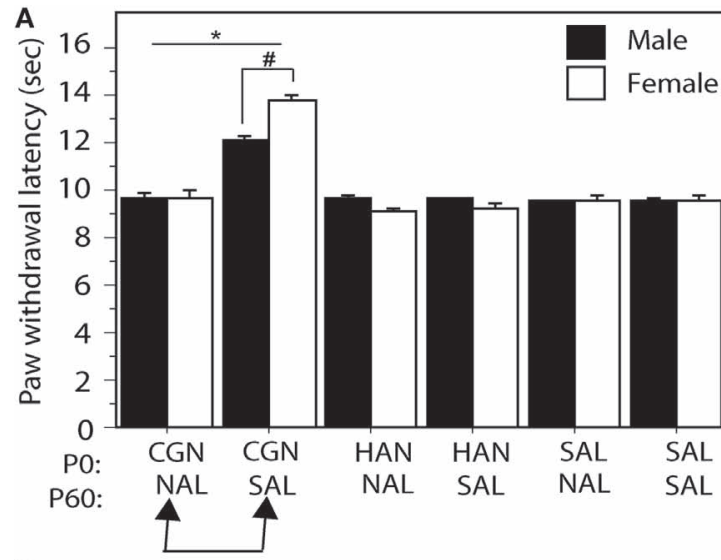

C

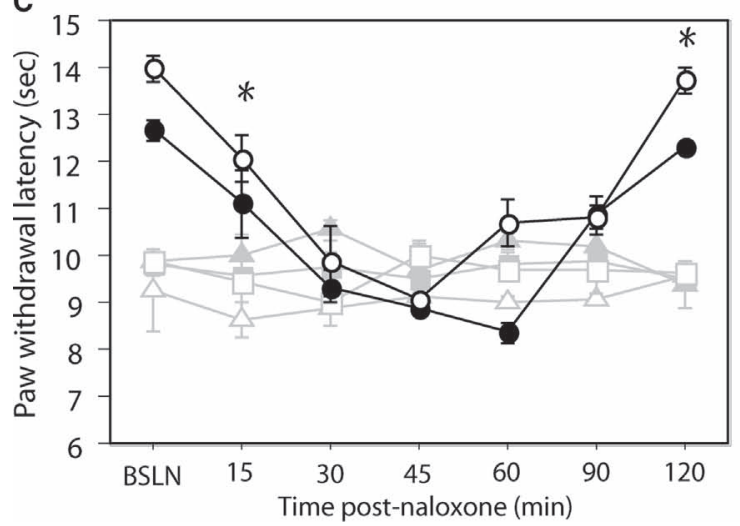

FIGURE 1 | (A) Administration of naloxone $\mathrm{HCl}$ to neonatally injured animals (CGN/NAL) prior to testing at P60 significantly lowered PWLs in comparison to injured animals that received saline (CGN/SAL). Administration of naloxone $\mathrm{HCL}$ to saline (SAL/NAL) or handled (HAN/NAL) controls had no effect. (B) Administration of naloxone methiodide (NAL-M) to neonatally injured (CGN/NAL-M) animals at P60 had no significant effect on PWLs compared to injured animals that received saline (CGN/SAL). Neonatally injured animals (CGN/NAL-M and CGN/SAL) displayed significantly higher PWLs compared to saline (SAL/NAL-M and

antagonist naloxone methiodide $(1 \mathrm{mg} / \mathrm{kg})$ prior to behavioral testing. This dose has been previously shown to block the peripheral but not central effects of morphine (Ji et al., 2006).

Administration of the naloxone methiodide had no effect on neonatal injury-induced hypoalgesia (Figure 1B). In contrast, intracerebroventricular administration of naloxone $\mathrm{HCl}(1 \mu \mathrm{g} / 2 \mu \mathrm{l})$, significantly decreased PWLs in neonatally injured animals to control levels at 30-min post-administration $(F(12,132)=15.87$, $p<0.05$; Figure 1C). Withdrawal latencies in injured animals returned to pre-injection levels 120-min following administration of naloxone $\mathrm{HCl}$. In contrast, i.c.v. naloxone $\mathrm{HCl}$ had no effect on withdrawal latencies in handled and saline control animals. Together, these results suggest that neonatal inflammation results in persistent changes in opioid tone that are centrally mediated.

\section{CHANGES IN OPIOID TONE ARE MEDIATED WITHIN THE PAG}

The PAG is an essential substrate for opioid-induced analgesia (Basbaum and Fields, 1978, 1984; Fields et al., 1991). To test the hypothesis that neonatal injury-induced alterations in opioid tone were mediated within the PAG, we administered naloxone $\mathrm{HCl}$ directly

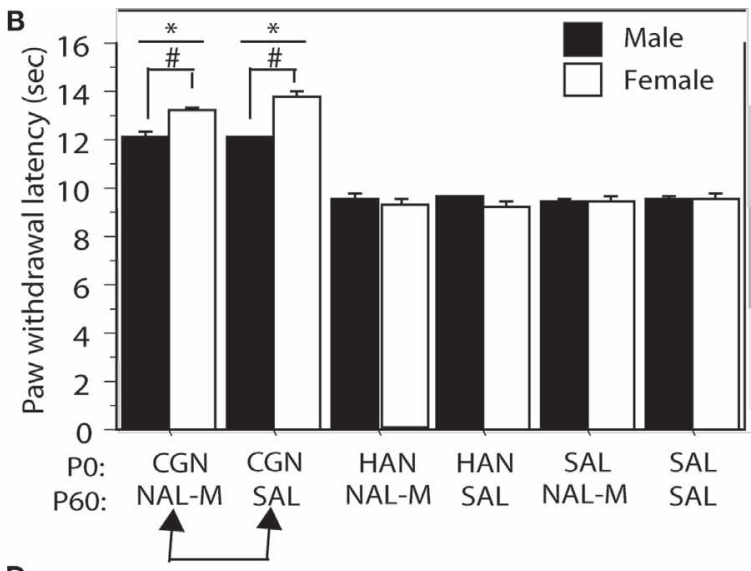

D

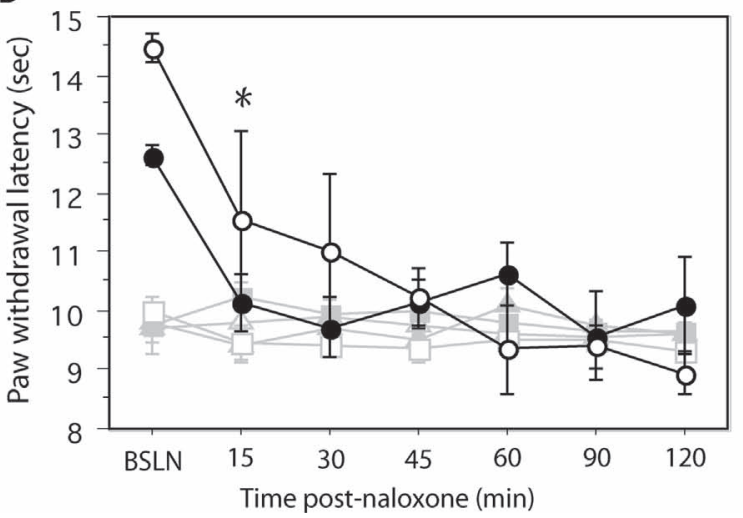

SAL/SAL) and handled (HAN/NAL-M and HAN/SAL) controls. (C) Neonatally injured males $(O)$ and females $(O)$ displayed significantly reduced PWLs during the 120 min following i.c.v. or (D) intra-PAG administration of naloxone $\mathrm{HCl}$ compared to handled males $(\Delta)$ or females $(\triangle)$ and saline males $(\square)$ and females $(\square)$. $N=6-8$ rats per group/per sex. In panels $(\mathbf{A})$ and $(\mathbf{B})$ : * denotes significant main effect of treatment; \# denotes significant main effect of sex; in panels (C) and (D) - * indicates that PWLs for injured animals (collapsed across sex) were significantly different from controls. Error bars represent SEM.

into the mid ventrolateral PAG (PAGvl) in neonatally injured and control animals. Intra-PAGvl naloxone $(0.5 \mu \mathrm{g} / 0.5 \mu \mathrm{l})$ significantly reduced PWLs in neonatally injured males and females at $15 \mathrm{~min}$ post-injection $(F(12,144)=8.95, p<0.05$; Figure 1D). No effect of intra-PAGvl naloxone was noted on PWLs in control animals.

The PAG contains mu, delta and kappa receptors (Mansour et al., 1995); therefore, to determine which opioid receptor subtype(s) in the PAG contribute to alterations in opioid tone, we administered receptor specific opioid antagonists. Intra-PAGvl administration of the mu receptor antagonist, CTOP $(7.5 \mu \mathrm{g} / 0.5 \mu \mathrm{l})$ significantly reduced PWLs in injured males and females to a level comparable to control values at 30 min post-injection $(F(12,108)=9.21, p<0.05$; Figure $2 \mathrm{~A})$. IntraPAGvl naltrindole $(7.5 \mu \mathrm{g} / 0.5 \mu \mathrm{l})$, a delta-selective antagonist, also significantly decreased PWLs to control levels, but only in neonatally injured females $(F(12,144)=2.92, p<0.05$; Figure 2B $)$. In males, the effects of intra-PAGvl naltrindole were limited to the first $15 \mathrm{~min}$ post-injection, with only a slight, albeit significant, decrease in PWLs observed. Intra-PAGvl administration of nor-BNI did not significantly reduce withdrawal latencies in injured males or females: significant main effect of injury, $F(2,42)=474.25, p<0.05$; Figure 2C. 


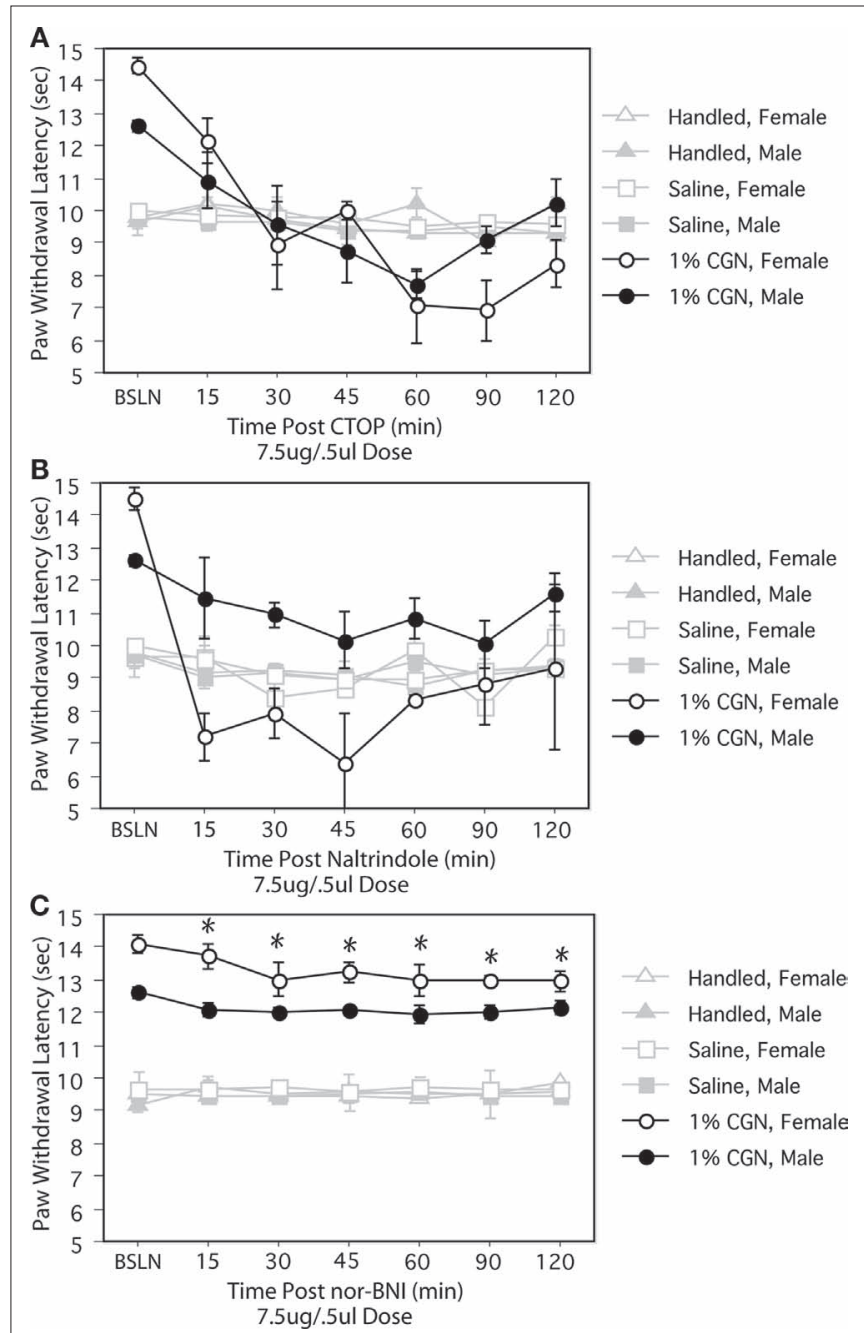

FIGURE 2 | (A) Intra-PAGvl CTOP significantly reduced PWLs in neonatally injured males $(\mathbf{)}$ ) and females $(\bigcirc)$ compared to controls. (B) Neonatally injured females displayed significantly reduced PWLs following intra-PAGvl naltrindole that were not significantly different from handled and saline controls. In males, intra-PAGvl naltrindole resulted in a slight decrease in PWLs. (C) Administration of nor-BNI into the PAGvl had no significant effect on PWLs in neonatally injured or control animals. $N=6-8$ rats per group/per sex. * indicates that PWLs for injured animals (collapsed across sex) were significantly different from controls.

\section{INJURY-INDUCED INCREASE BETA-ENDORPHIN AND MET/LEU-ENKEPHALIN IMMUNOREACTIVITY IN THE PAG}

The next series of experiments used immunohistochemistry and receptor autoradiography to determine whether our behavioral pharmacological results reflected changes in endogenous opioid peptide and/or receptor expression within the PAG.

Beta-endorphin, an endogenous opioid neuropeptide that has the highest affinity for mu opioid receptors, was significantly increased in the lateral/ventrolateral $(1 / \mathrm{vl})$ region of the $\operatorname{mid}(F(1,16)=4.62$, $p<0.05)$ and caudal $(F(1,16)=6.57, p<0.05)$ PAG in neonatally injured males and females compared to handled controls (Figure 3). Increases in beta-endorphin were primarily evidenced as an increase in the number of immunoreactive fibers within the ventrolateral PAG. No significant injury effects were observed in the rostral PAG. Moreover, no significant sex differences in betaendorphin expression were detected at any level of the PAG.

Neonatal injury also induced changes in the expression of the DOR preferring ligands, met-and leu-enkephalin. Specifically, neonatally injured males and females displayed significantly increased met- and leu-enkephalin immunoreactivity in the $1 / \mathrm{vl}$ region of the mid (met: $F(1,20)=29.50, p<0.05$; leu: $F(1,20)=14.92, p<0.05)$ and caudal (met: $F(1,20)=50.88, p<0.05$; leu: $F(1,20)=13.23$, $p<0.05$ ) levels of the PAG compared to controls (Figure 4). For both met- and leu-enkephalin, neonatal injury induced an increase in both the number and density of fiber staining; changes in immunoreactivity were primarily limited to the lateral PAG. A significant effect of sex was noted within the mid and caudal PAGl/vl for met-enkephalin, such that injured females displayed significantly more immunoreactive fibers compared to injured males (mid: $F(1,20)=5.39, p<0.05$; caudal: $F(1,20)=4.72, p<0.05)$.

\section{DECREASED MOR AND DOR BINDING IN THE PAG}

We next used autoradiography to determine if neonatal injury was also associated with changes in opioid receptor binding. Neonatally injured males and females displayed significantly reduced MOR binding at all rostral-caudal levels of the PAGl/vl compared to handled controls (rostral: $F(1,20)=58.46, p<0.05$; mid: $F(1,20)=286.50, p<0.05$; caudal: $F(1,20)=78.89, p<0.05$; Figure 5). Immunohistochemistry was also used to confirm our observed decrease in PAG MOR expression. Similar to what we observed using autoradiography, neonatal injury resulted in a significant decrease in MOR immunoreactivity (primarily due to decreased fiber staining) within the mid $(F(1,20)=26.34$, $p<0.05)$ and caudal $(F(1,20)=31.51, p<0.05)$ levels of the $\mathrm{PAGl} / \mathrm{vl}$ (Figure 6). Neonatal injury induced decreases in MOR were also evident within the dorsolateral PAG.

A significant decrease in DOR binding was also observed at the mid level $(F(1,20)=22.41, p<0.05)$ of the PAGl/vl in neonatally injured females compared to all other groups (Figure 5). The sexually dimorphic expression of DOR binding in injured animals is consistent with our behavioral effects showing sex-specific effects of intra-PAG naltrindole on baseline thermal sensitivity (Figure 2B). As there are no DOR-specific antibodies that are commercially available, corroboration of the binding data with immunocytochemistry could not be performed.

\section{DISCUSSION}

Our principle finding is that the hypoalgesia induced by neonatal inflammatory insult is mediated by changes in mu and delta, but not kappa, opioid tone within the PAG, as indicated by an increase in endogenous opioid peptide expression (beta-endorphin and met/leu-enkephalin), and a concomitant decrease in mu and delta opioid receptor binding. Changes in delta opioid tone were sex specific, and may contribute to the potentiated effects of neonatal injury observed in females.

The periaqueductal gray (PAG), and its descending projections to the rostral ventromedial medulla (RVM) and the spinal cord dorsal horn, constitute a primary anatomical circuit for the descending modulation of pain (Basbaum and Fields, 1984). The PAG is rich in nerve terminals and fibers containing endogenous 

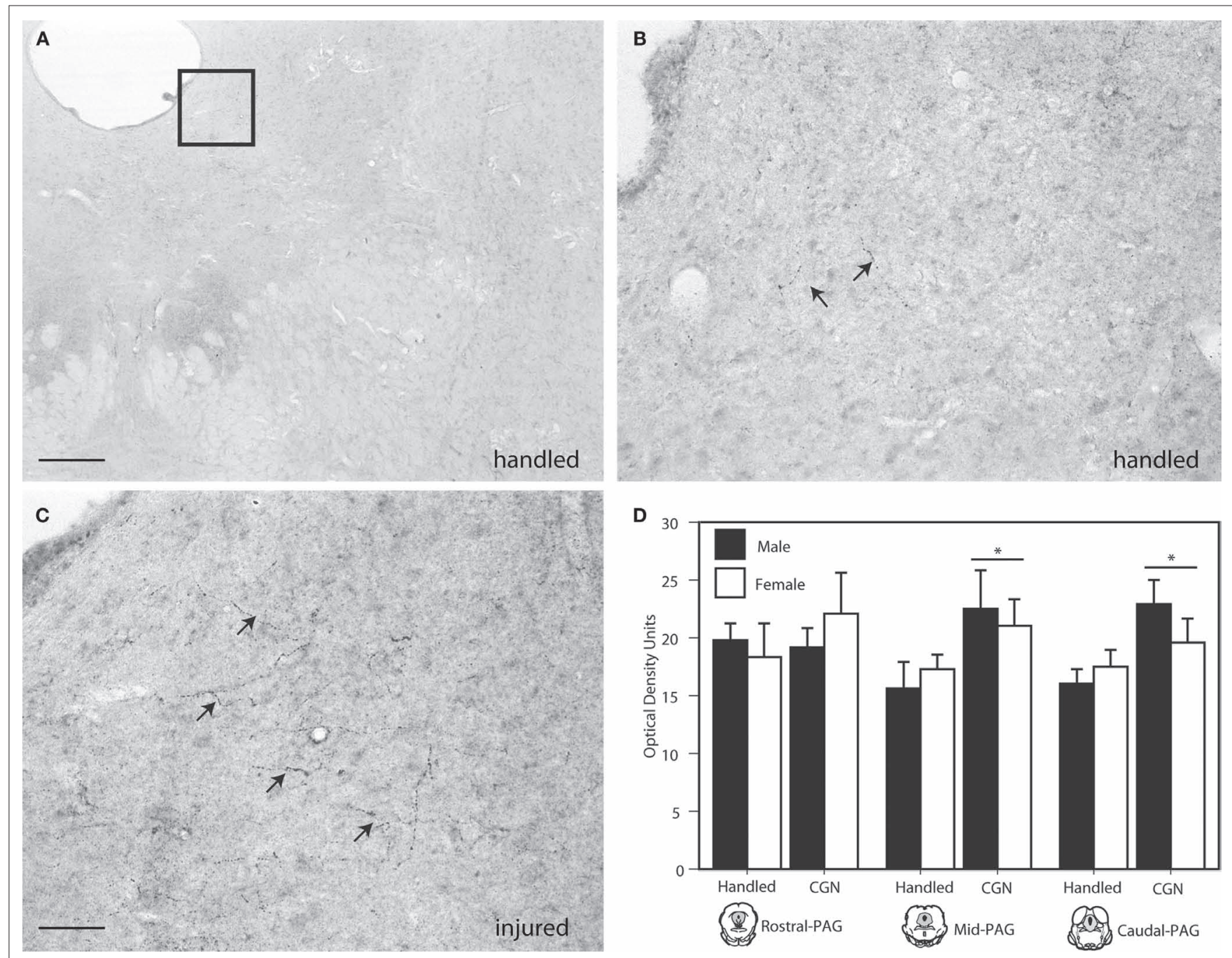

FIGURE 3 | Photomicrograph depicting representative examples of beta-endorphin-ir in the PAGI/vl in adult rats following neonatal treatment.

(A) handled, 4x, (B) handled, 20x; (C) 1\% carrageenan, 20x. (D) Neonatal CGN resulted in significantly increased beta-endorphin-ir in the lateral/ventrolateral regions of the mid and caudal PAG compared to control animals. $N=6-8$ rats per group/per sex. ${ }^{*}$ denotes significant main effect of treatment. Error bars represent SEM.

opioids (Reichling et al., 1988), and opioid receptors are localized throughout the rostral-caudal axis of the PAG (Mansour et al., 1995). Interestingly, while in rats the anatomical connections for nociceptive modulation are present at birth, descending inhibitory controls are functionally immature throughout the first postnatal weeks (Fitzgerald and Koltzenburg, 1986; Boucher et al., 1998). The delayed maturation of descending inhibition may therefore contribute to the increased vulnerability of the immature somatosensory system to excessive afferent input, whereby exposure to neonatal noxious stimulation during a critical window may alter the functional integrity of endogenous descending inhibitory systems. In reference to the present results, our working hypothesis is that neonatal injury during this critical developmental period ( $\mathrm{P} 0$ P8; LaPrairie and Murphy, 2007) results in increased afferent drive to CNS sites responsive to noxious input (e.g. PAG). This increased drive results in the activation of endogenous pain inhibitory circuits and the subsequent release of endogenous opioid peptides. As the inflammation associated with intraplantar carrageenan is persistent (lasting approximately 48-72 h), the release of endogenous opioids is sustained, and this continuous opioid release, during a time of increased developmental plasticity, is subsequently maintained into adulthood. Previous studies have reported that increased afferent drive during the developmental critical period results in the reorganization of somatosensory circuits in adulthood (Tropea et al., 2006). Indeed, changes in endogenous pain modulation in humans as a consequence of neonatal pain has been previously proposed to account for the long term changes in pain sensitivity observed in NICU infants exposed to frequent noxious interventions (Goffaux et al., 2008).

In the present study, we report a significant increase in PAG opioid peptide expression as a consequence of neonatal injury, and it is notable that alterations in the endorphin and enkephalinergic systems were very well correlated across similar regions and levels of the PAG. This suggests that the two opioidergic systems act in parallel in response to neonatal inflammation and nociception. While comparable studies have not been conducted in neonates, previous studies 


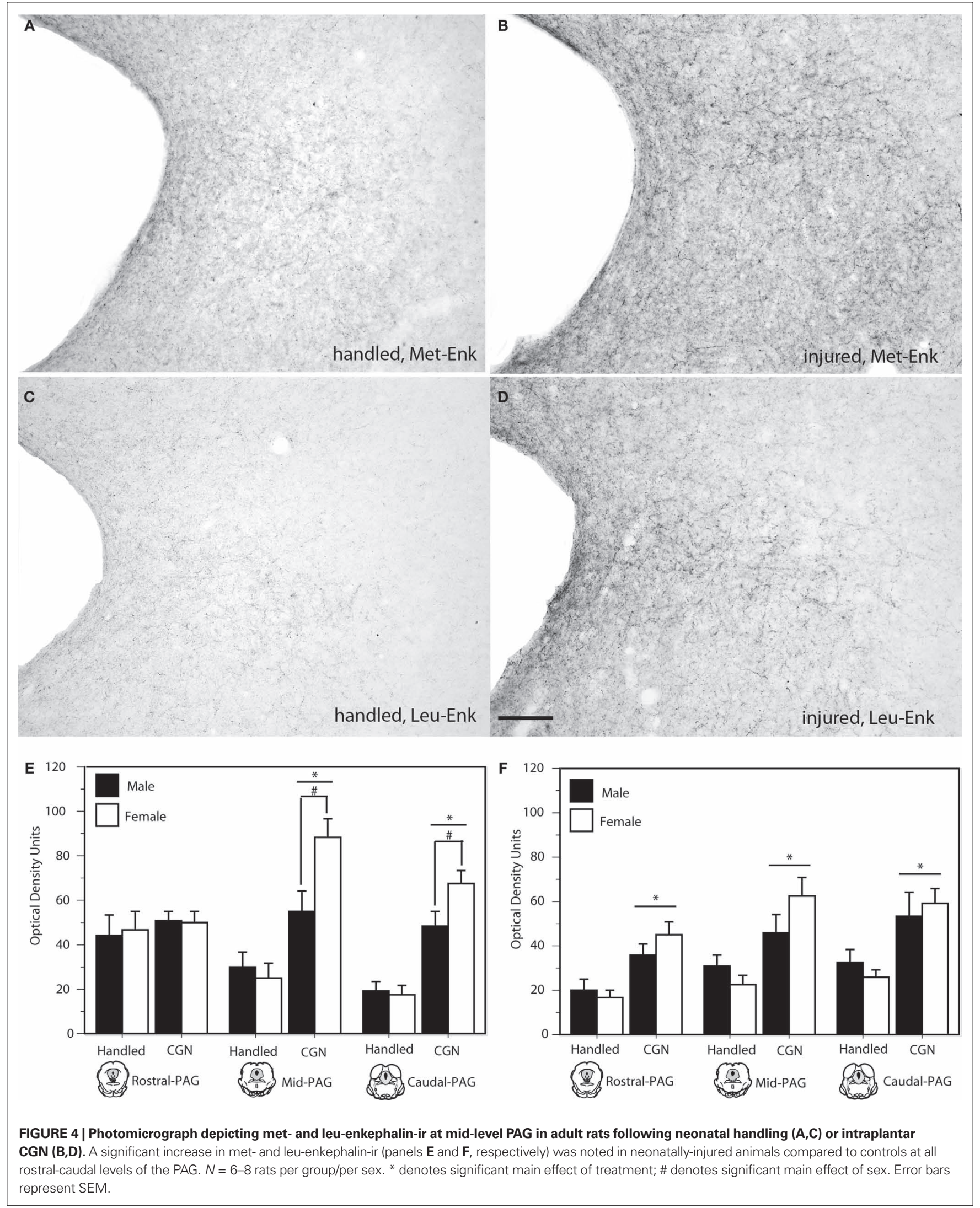



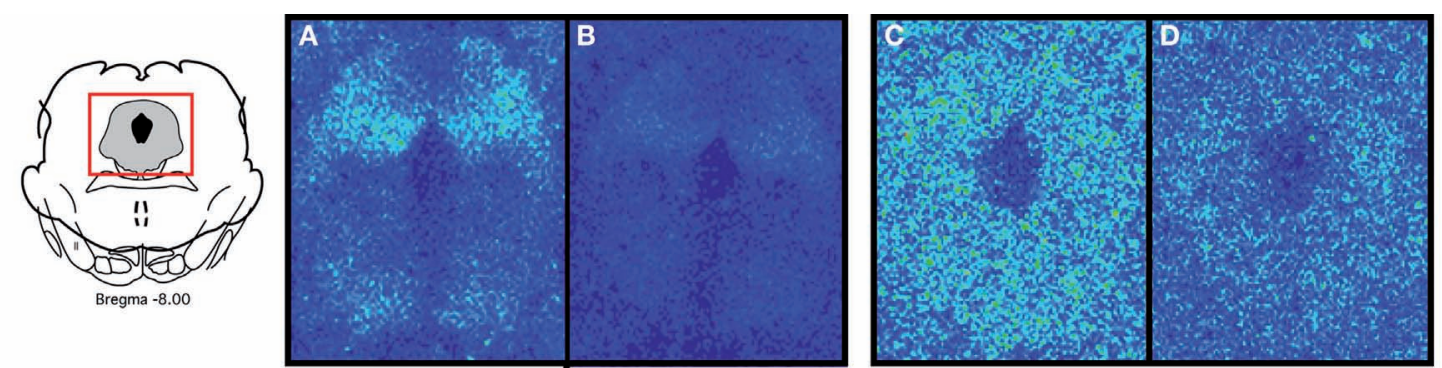

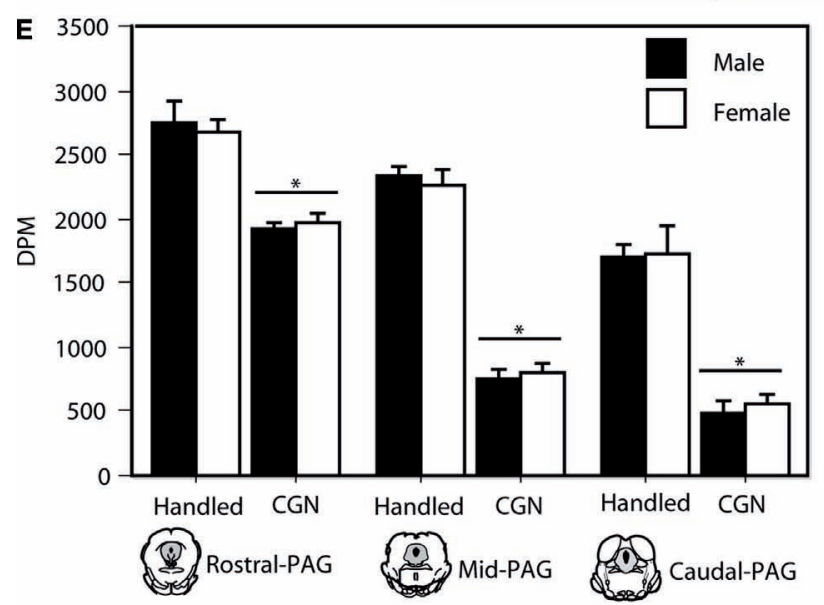

FIGURE 5 | MOR binding in the PAG in adult rats following (A) handling, or (B) $1 \%$ carrageenan. DOR binding distribution in the PAG of adult rats following (C) handling, or (D) $1 \%$ carrageenan. (E) Neonatally injured (CGN) animals displayed a significant decrease in MOR-binding at all levels of the PAGI/vl compared to handled animals. (F) A significant decrease in

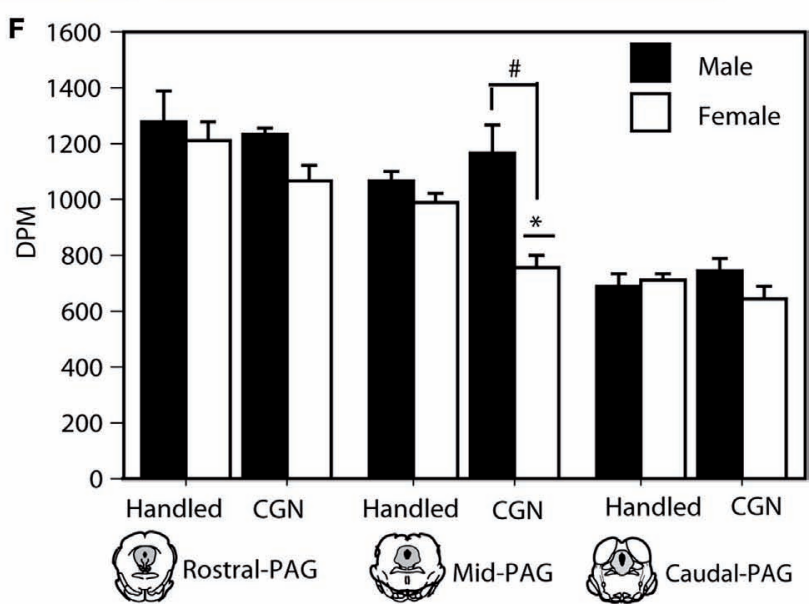

DOR-binding was noted in neonatally injured females in comparison to all other groups in the mid PAGI/vl. A significant main effect of sex was also observed at this level. $N=6$ rats per group/per sex. ${ }^{*}$ denotes significant main effect of treatment; \# denotes significant main effect of sex. Error bars represent SEM. in adult rats have reported that hindpaw inflammation results in upregulated biosynthesis of pro-dynorphin and pro-enkephalin in dorsal horn neurons (Iadarola et al., 1988; Noguchi et al., 1989), and a significant increase in endogenous opioid peptide release within the PAG (Williams et al., 1995). Noxious stimulation-induced changes in opioid peptide expression are also paralleled by an increase in mRNA expression (Iadarola et al., 1988). As stated above, our working hypothesis is that neonatal inflammation results in the release of endogenous opioid peptides within the PAG as a mechanism of decreasing nociception. It is not clear why a parallel decrease in opioid receptor expression was also noted. However, previous studies have similarly reported a long-term increase in endogenous opioid peptide along with a concomitant decrease in mu and delta opioid receptor density in the lateral hypothalamus of offspring following gestational stress (Sanchez et al., 1996, 2000). Alternatively, opioid receptors are rapidly internalized following ligand binding, which would also result in a concomitant decrease in opioid receptor availability. Taken together, these studies suggest that early life pain can confer long-lasting changes in supraspinal opioidergic circuits that are reflected by changes in peptide and receptor expression.

In the present study, intra-PAG naloxone significantly reduced neonatal injury-induced hypoalgesia suggesting a locus for injuryinduced changes. However, neonatal inflammatory insult may induce changes in opioid tone in other sites, including the RVM and spinal cord. Indeed, increased brain and spinal cord immunoreactive beta-endorphin, met-enkephalin and dynorphin, as well as decreased opioid receptor binding has been reported following peripheral inflammation in adult rats (Cesselin et al., 1980; Millan et al., 1986; Spetea et al., 2002). Therefore, while the results of our site-specific antagonist injections suggest that changes in the PAG are necessary and sufficient for the observed effects of neonatal injury, changes in additional CNS sites cannot be excluded.

A significantly greater increase in met-enkephalin was observed in neonatally injured females compared to males. This differential change in peptide expression may contribute to the increased hypoalgesia observed in females. No significant sex difference in met-enkephalin immunoreactivity was present at baseline, indicating that the observed sex differences were injury-induced. Although not investigated in the present study, endomorphins also play an important role in the modulation of descending controls, and possess partial agonist properties at mu-receptor sites in the PAG (Zadina et al., 1997).

While the results of the present study strongly suggest that persistent alterations in baseline nociceptive thresholds associated with neonatal inflammatory insult are mediated by a central increase in endogenous opioid tone, additional mechanisms may also contribute. Noxious neonatal experiences lead not only to decreased nociceptive sensitivity in adulthood, but also to significant alterations in the behavioral and neuroendocrine responses to stress (Bernardi et al., 1986; Anand et al., 1999; Bhutta et al., 2001; Schellinck et al., 2003; Sternberg and Ridgway, 2003; Sternberg et al., 

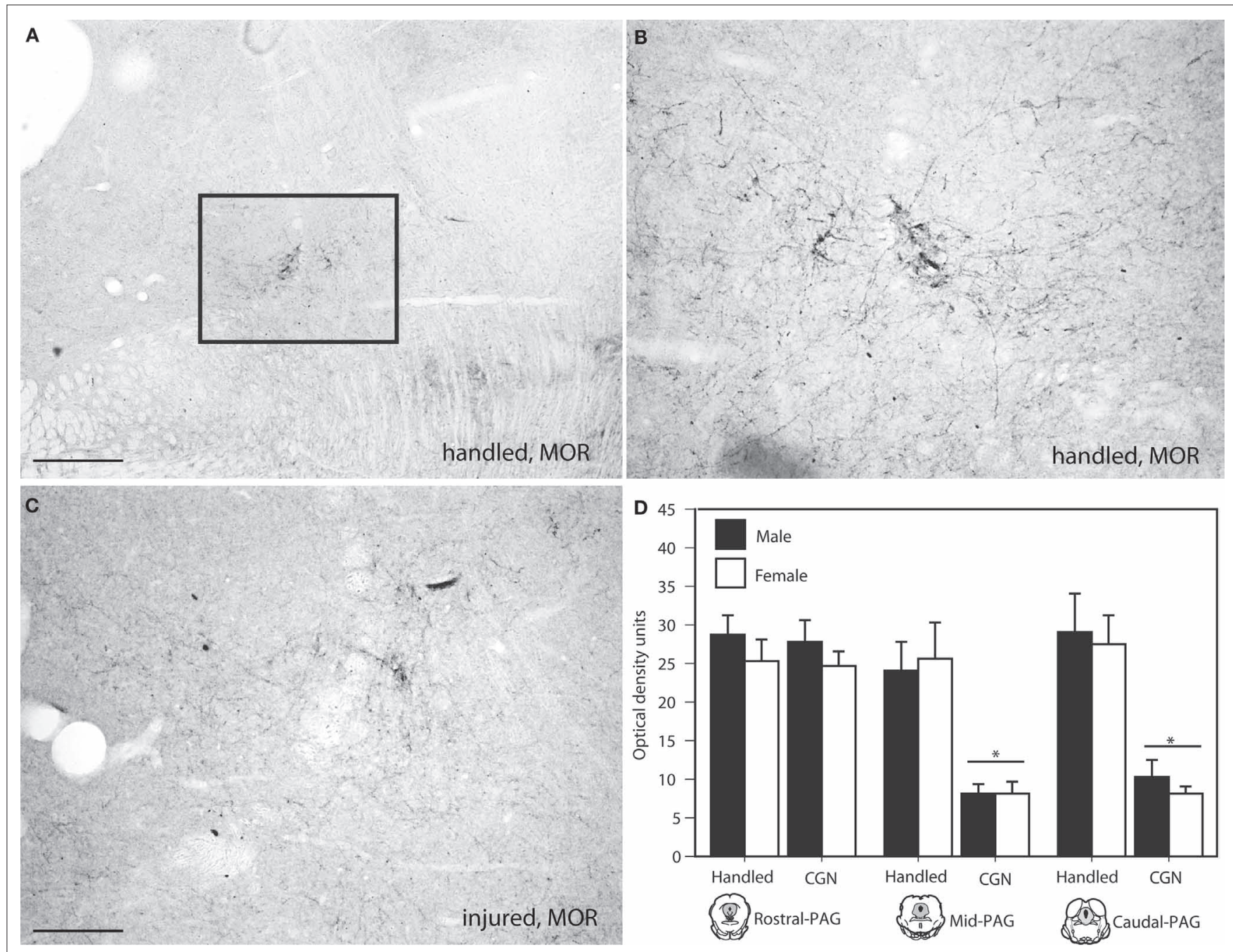

FIGURE 6 | Photomicrograph depicting representative examples of MOR-ir in the PAGI/vl in adult rats following neonatal treatment. (A) handled, $4 \times$

(B) handled, 10x, (C) 1\% carrageenan, 10x. (D) At mid and caudal levels of PAG,
CGN animals expressed significantly lower MOR-ir compared to handled animals. $N=6-8$ rats per group/per sex. ${ }^{*}$ denotes significant main effect of treatment. Error bars represent SEM.
2005). Blunted emotionality, decreased anxiety, and reduced basal and stress induced plasma corticotropin releasing factor (CRF) and adrenocorticotropin hormone (ACTH) are displayed in adult rats following short-lasting, local inflammation experienced during the first week of life (Bhutta et al., 2001; Anseloni et al., 2005). Premature infants with extensive NICU care also exhibit low basal levels of stress hormones at 3 months of age compared to their full-term counterparts (Grunau et al., 2007). Thus, alterations in the developing hypothalamic-pituitary-adrenal axis may also contribute to the long-term basal hypoalgesia following neonatal hindpaw inflammation. Indeed neonatal noxious stimulation may produce a generalized reduction in reactivity to aversive environmental stimuli due to parallel alterations in supraspinal nociceptive and stress modulatory circuits (Ren et al., 2004; Anseloni et al., 2005). Ongoing studies in our laboratory are currently testing this hypothesis.

In summary, the present study demonstrated that persistent pain experienced early in life results in decreased mu and delta receptor availability, suggesting a persistent activation of opioid receptors due to enhanced release of endogenous opioid peptides. This decrease in receptor availability is supported by our previous findings demonstrating a significant rightward shift in the morphine dose-response curve in adult animals that were neonatallyinjured (LaPrairie et al., 2008). Similar results have been reported in children, such that the number of invasive procedures experienced in the neonatal intensive care unit are inversely correlated with morphine effectiveness (Grunau et al., 2001). Despite the current knowledge that neonates are responsive to noxious stimuli, the majority of routine procedures, including repeated heel-lances, endotracheal intubations and minor surgeries are performed in the absence of analgesics (Simons et al., 2003). Indeed recent studies have reported that neonates receiving NICU treatment experience an average of 14 noxious procedures per day, with fewer than $35 \%$ receiving appropriate analgesic therapy (Simons et al., 2003). Demonstration that neonatal injury results in long-term changes in opioid tone and sensory thresholds may have serious implications for future pain management in neonates. 


\section{ACKNOWLEDGMENTS}

This work was supported by National Institute of Health grants DA16272 and AR49555 awarded to Anne Z. Murphy, the Center for Behavioral Neuroscience NSF: IBN 9876754, and the Georgia

\section{REFERENCES}

Al-Chaer, E. D., Kawasaki, M., and Pasricha, P. J. (2000). A new model of chronic visceral hypersensitivity in adult rats induced by colon irritation during postnatal development. Gastroenterology 119, 1276-1285.

Anand,K.J.,Coskun,V., Thrivikraman, K.V., Nemeroff, C. B., and Plotsky, P. M. (1999). Long-term behavioral effects of repetitive pain in neonatal rat pups. Physiol. Behav. 66, 627-637.

Anseloni, V. C., He, F., Novikova, S. I., Turnbach Robbins, M., Lidow, I. A., Ennis, M., and Lidow, M. S. (2005). Alterations in stress-associated behaviors and neurochemical markers in adult rats after neonatal shortlasting local inflammatory insult. Neuroscience 131, 635-645.

Basbaum, A. I., and Fields, H. L. (1978). Endogenous pain control mechanisms: review and hypothesis. Ann. Neurol. 4, 451-462.

Basbaum, A. I., and Fields, H. L. (1984). Endogenous pain control systems: brainstem spinal pathways and endorphin circuitry. Annu. Rev. Neurosci. 7, 309-338.

Bernardi, M., Genedani, S., and Bertolini, A. (1986). Behavioral activity and active avoidance learning and retention in rats neonatally exposed to painful stimuli. Physiol. Behav. 36, 553-555.

Bhutta,A. T., Rovnaghi, C., Simpson, P. M., Gossett, J. M., Scalzo, F. M., and Anand, K. J. (2001). Interactions of inflammatory pain and morphine in infant rats: long-term behavioral effects. Physiol. Behav. 73, 51-58.

Boucher, T., Jennings, E., and Fitzgerald, M. (1998). The onset of diffuse noxious inhibitory controls in postnatal rat pups: a C-Fos study. Neurosci. Lett. 257, 9-12.

Cesselin, F., Montastruc, J. L., Gros, C., Bourgoin, S., and Hamon, M. (1980). Met-enkephalin levels and opiate receptors in the spinal cord of chronic suffering rats. Brain Res. 191, 289-293.

Commons, K. G., Aicher, S. A., Kow, L. M., and Pfaff, D. W. (2000). Presynaptic and postsynaptic relations of mu-opioid receptors to gammaaminobutyric acid-immunoreactive and medullary-projecting periaqueductal gray neurons. J. Comp. Neurol. 419, 532-542.

Craft, R. M., Tseng, A. H., McNiel, D. M., Furness, M. S., and Rice, K. C. (2001).
Receptor-selective antagonism of opioid antinociception in female versus male rats. Behav. Pharmacol. 12 591-602.

DeBerry, J., Ness, T. J., Robbins, M. T., and Randich, A. (2007). Inflammationinduced enhancement of the visceromotor reflex to urinary bladder distention: modulation by endogenous opioids and the effects of early-in-life experience with bladder inflammation. J. Pain. 8, 914-923.

Fields, H. L., Heinricher, M. M., and Mason, P. (1991). Neurotransmitters in nociceptive modulatory circuits. Annu. Rev. Neurosci. 14, 219-245.

Fitzgerald, M., and Koltzenburg, M. (1986). The functional development of descending inhibitory pathways in the dorsolateral funiculus of the newborn rat spinal cord. Brain Res. 389, 261-270.

Goffaux, P., Lafrenaye, S., Morin, M., Patural, H., Demers, G., and Marchand, S. (2008). Preterm births: can neonatal pain alter the development of endogenous gating systems? Eur. J. Pain. 12, 945-951.

Grunau,R.E.,Haley,D.W., Whitfield, M. F., Weinberg, J., Yu, W., and Thiessen, P. (2007). Altered basal cortisol levels at $3,6,8$ and 18 months in infants born at extremely low gestational age. J. Pediatr. 150, 151-156.

Grunau, R. E., Oberlander, T. F., Whitfield, M. F., Fitzgerald, C., and Lee, S. K. (2001). Demographic and therapeutic determinants of pain reactivity in very low birth weight neonates at 32 weeks' postconceptional age. Pediatrics 107, 105-112.

Grunau, R. V., Whitfield, M. F., and Petrie, J. H. (1994a). Pain sensitivity and temperament in extremely lowbirth-weight premature toddlers and preterm and full-term controls. Pain 58, 341-346.

Grunau, R. V., Whitfield, M. F., Petrie, J. H., and Fryer, E. L. (1994b). Early pain experience, child and family factors, as precursors of somatization: a prospective study of extremely premature and fullterm children. Pain 56, 353-359.

Hargreaves, K., Dubner, R., Brown, F., Flores, C., and Joris, J. (1988). A new and sensitive method for measuring thermal nociception in cutaneous hyperalgesia. Pain 32, 77-88.

Hermann,C.,Hohmeister,J.,Demirakca, S., Zohsel, K., and Flor, H. (2006). Longterm alteration of pain sensitivity in

State University Brains and Behavior Program. The authors are grateful for the constructive comments provided by Michael S. Gold and Larry Young on a previous version of this manuscript, and to Erica Famojure for technical assistance.

school-aged children with early pain experiences. Pain 125, 278-285.

Hiller, J. M., Zhang, Y., Bing, G., Gioannini, T. L., Stone, E. A., and Simon, E. J. (1994). Immunohistochemical localization of mu-opioid receptors in rat brain using antibodies generated against a peptide sequence present in a purified mu-opioid binding protein. Neurosci. $62,829-841$.

Iadarola, M. J., Douglass, J., Civelli, O., and Naranjo, J. R. (1988). Differential activation of spinal cord dynorphin and enkephalin neurons during hyperalgesia: evidence using cDNA hybridization. Brain Res. 455, 205-212.

Ji, Y., Murphy, A. Z., and Traub, R. J. (2006). Sex differences in morphineinduced analgesia of visceral pain are supraspinally and peripherally mediated. Am. J. Physiol. Regul. Integr. Comp. Physiol. 291, R307-R314.

Johnston, C. C., Stevens, B., Yang, F., and Horton, L. (1996). Developmental changes in response to heelstick in preterm infants: a prospective cohort study. Dev. Med. Child Neurol. 38 438-445.

LaPrairie, J. L., Johns, M. E., and Murphy, A. Z. (2008). Preemptive morphine analgesia attenuates the long-term consequences of neonatal inflammation in male and female rats. Pediatr. Res. 64, 625-630.

LaPrairie, J. L., and Murphy, A. Z. (2007). Female rats are more vulnerable to the long-term consequences of neonatal inflammatory injury. Pain 132(Suppl. 1), S124-S133.

Loyd, D. R., Morgan, M. M., and Murphy, A.Z. (2008). Sexually dimorphic activation of the periaqueductal gray-rostral ventromedial medullary circuit during the development of tolerance to morphine in the rat. Eur. J. Neurosci. 27, 1517-1524.

Mansour, A., Fox, C. A., Burke, S., Akil, H., and Watson, S. J. (1995). Immunohistochemical localization of the cloned mu opioid receptor in the rat CNS. J. Chem. Neuroanat. 8 , 283-305.

Millan,M.J.,Millan,M.H.,Czlonkowski, A., Hollt, V., Pilcher, C. W., Herz, A., and Colpaert, F. C. (1986). A model of chronic pain in the rat: response of multiple opioid systems to adjuvant-induced arthritis. J. Neurosci. 6 , 899-906.

Noguchi, K., Morita, Y., Kiyama, H., Sato, M., Ono, K., and Tohyama, M.
(1989). Preproenkephalin gene expression in the rat spinal cord after noxious stimuli. Brain Res. Mol. Brain Res. 5, 227-234

Oberlander, T. F., Grunau, R. E., Whitfield, M. F., Fitzgerald, C., Pitfield, S., and Saul, J. P. (2000). Biobehavioral pain responses in former extremely low birth weight infants at four month' corrected age. Pediatrics 105, e6.

Reichling, D. B., Kwiat, G. C., and Basbaum, A. I. (1988). Anatomy, physiology and pharmacology of the periaqueductal gray contribution to antinociceptive controls. Prog. Brain Res. 77, 31-46.

Ren, K., Anseloni, V.,Zou, S.P., Wade, E. B., Novikova, S. I., Ennis, M., Traub, R. J., Gold,M.S.,Dubner,R., andLidow, M. S. (2004). Characterization of basal and re-inflammation-associated long-term alteration in pain responsivity following short-lasting neonatal local inflammatory insult. Pain 110, 588-596.

Sanchez, M. D., Milanes, M. V., Pazos, A., Diaz, A., and Laorden, M. L. (1996) Autoradiographic evidence of muopioid receptors down-regulation after prenatal stress in offspring rat brain. Brain Res. Dev. Brain Res. 94, 14-21.

Sanchez, M. D., Milanes, M. V., Pazos, A., Diaz, A., and Laorden, M. L. (2000). Autoradiographic evidence of deltaopioid receptor downregulation after prenatal stress in offspring rat brain. Pharmacology 60, 13-18.

Schellinck, H. M., Stanford, L., and Darrah, M. (2003). Repetitive acute pain in infancy increases anxiety but does not alter spatial learning ability in juvenile mice. Behav. Brain Res. 142, 157-165.

Shimada, C., Kurumiya, S., Noguchi, Y., and Umemoto, M. (1990). The effect of neonatal exposure to chronic footshock on pain-responsiveness and sensitivity to morphine after maturation in the rat. Behav Brain Res. 36, 105-111.

Simons, S. H., van Dijk, M., Anand, K. S., Roofthooft, D., van Lingen, R. A., and Tibboel, D. (2003). Do we still hurt newborn babies? A prospective study of procedural pain and analgesia in neonates. Arch. Pediatr. Adolesc. Med. 157, 1058-1064.

Spetea, M., Rydelius, G., Nylander, I., Ahmed, M., Bileviciute-Ljungar, I., Lundeberg, T., Svensson, S., and Kreicbergs, A. (2002). Alteration in endogenous opioid systems due to chronic inflammatory pain 
conditions. Eur. J. Pharmacol. 435, 245-252.

Sternberg, W. F., and Ridgway, C. G. (2003). Effects of gestational stress and neonatal handling on pain, analgesia, and stress behavior of adult mice. Physiol. Behav. 78, 375-383.

Sternberg, W. F., Scorr, L., Smith, L. D., Ridgway, C. G., and Stout, M. (2005). Long-term effects of neonatal surgery on adulthood pain behavior. Pain 113, 347-353.

Tropea, D., Kreiman, G., Lyckman, A., Mukherjee, S., Yu, H., Horng, S., and Sur, M. (2006). Gene expression changes and molecular pathways mediating activity-dependent plasticity in visual cortex. Nat. Neurosci. 9, 660-668.

Wang, G., Ji, Y., Lidow, M. S., and Traub, R. J. (2004). Neonatal hind paw injury alters processing of visceral and somatic nociceptive stimuli in the adult rat. J. Pain 5, 440-449.

Wang, H., and Wessendorf, M. W. (2002). $\mathrm{Mu}$ - and delta-opioid receptor mRNAs are expressed in periaqueductal gray neurons projecting to the rostral ventromedial medulla. Neuroscience 109, 619-634

Watson,R.E.,Jr.,Wiegand,S.J.,Clough, R. W., and Hoffman, G. E. (1986). Use of cryoprotectant to maintain long-term peptide immunoreactivity and tissue morphology. Peptides 7, 155-159.
Williams, F. G., Mullet, M. A., and Beitz, A. J. (1995). Basal release of Met-enkephalin and neurotensin in the ventrolateral periaqueductal gray matter of the rat: a microdialysis study of antinociceptive circuits. Brain Res. 690, 207-216.

Zadina, J. E., Hackler, L., Ge, L. J., and Kastin, A. J. (1997). A potent and selective endogenous agonist for the muopiate receptor. Nature 386, 499-502.

Conflict of Interest Statement: The authors declare that the research was conducted in the absence of any commercial or financial relationships that could be construed as a potential conflict of interest.
Received: 24 July 2009; paper pending published: 04 August 2009; accepted: 27 August 2009; published online: 30 September 2009.

Citation: LaPrairie JL and Murphy AZ (2009) Neonatal injury alters adult pain sensitivity by increasing opioid tone in the periaqueductal gray. Front. Behav. Neurosci. 3:31. doi: 10.3389/neuro.08.031.2009

Copyright $\odot 2009$ LaPrairie and Murphy. This is an open-access article subject to an exclusive license agreement between the authors and the Frontiers Research Foundation, which permits unrestricted use, distribution, and reproduction in any medium, provided the original authors and source are credited. 